Jud, G. D., T. R. Wingler, and D. T. Winkler. “The Integration of Retail Space Markets,” Journal of Real Estate Portfolio Management, vol. 8, no. 1, 2002 , pp. 79-92. Made available courtesy of American Real Estate Society: http://www.aresnet.org/

***Reprinted with permission. No further reproduction is authorized without written permission from the American Real Estate Society.

This version of the document is not the version of record. Figures and/or pictures may be missing from this format of the document.***

\title{
The Integration of Retail Space Markets
}

Executive Summary. This study estimates optimized portfolios on an efficient frontier of real estate investment in the retail sector of fifty-eight metropolitan markets (MSAs), using quarterly sample data covering 19872000. The efficient opportunity sets and associated percentage allocations are determined for the entire sample of fifty-eight MSAs, as well as for subsets for each region of the country. Findings indicate that some regions offer much higher performance in a risk/return occupancy context than others. Also, the occupancy risk / return performance improves substantially when allocations are not limited to particular regions, suggesting that the retail space markets are relatively segmented.

* University of North Carolina-Greensboro, Greensboro, NC 27412-5001 and juddon@uncg.edu.

** University of North Carolina-Greensboro, Greensboro, NC 27412-5001 and tony_winglereuncg.edu.

$* * *$ University of North Carolina-Greensboro, Greensboro, NC 27412-5001 or dtwinkler@uncg.edu. by G. Donald Jud*

Tony R. Wingler**

Daniel T. Winkler****

\section{Introduction}

An important issue facing many real estate investors is whether to seek reductions in risk through geographic diversification. If space markets are integrated, then the price of risk is the same in all markets. In this case, diversification across markets achieves no reduction in risk. If metropolitan areas have their own real estate cycles and if the cycles are relatively uncorrelated with each other, then the benefits of diversification will be large. Alternatively, if markets are highly integrated, the payoff to diversification will be minimal.

The benefits of real estate diversification have been widely studied over the past two decades. Seiler, Webb and Myer (1999) review much of this research in a recent literature survey. Most of the diversification research has utilized return series derived from indexes developed by the National Council of Real Estate Investment Fiduciaries (NCREIF). The NCREIF data track quarterly appraisal-based returns by sector for a limited number of metropolitan statistical areas (MSAs), and the return series apply only to real estate held in private equity portfolios. For real estate investment trust (REIT) portfolios, there is no geographic return series that managers can use when applying standardized asset allocation methodologies. REIT managers could, of course, employ the NCREIF data, but given the low correlation of the NCREIF series with REIT returns, this approach may be questionable.

This study explores a different approach. Occupancy data obtained from F. W. Dodge is used to 
estimate optimized portfolios on an efficient frontier of real estate investment in the retail sector in fifty-eight metropolitan markets. Using this approach permits an evaluation of mean-variance efficiency for portfolios covering a larger number of MSAs than is available with the NCREIF series. By focusing on the retail sector, the benefits of geographic diversification can be concentrated on, abstract of sector diversification issues.

The article is divided into four sections. The next section provides a review of the relevant literature. Next, a discussion of the methodology and data used in the analysis is followed by the empirical results. Finally, the last section summarizes relevant findings and discusses possible extensions of the research.

\section{Literature Review}

A number of studies have explored the variation in real estate portfolio returns and how variation in returns is related to geographic location. Articles in this area include Hartzell, Schulman and Wurtzebach (1987), Hartzell, Heckman and Miles (1986), Corgel and Gay (1987), Malizia and Simons (1991) and Mueller (1993), among others. Goetzmann and Wachter (1995) apply a cluster analysis to vacancy rate data from twenty-two metropolitan statistical areas (MSAs). They find that the MSAs tend to cluster into a smaller number of "family" groups and that these groupings are related to the dominant industries in each cluster. The implication of their research is that real estate diversification can be obtained by diversifying among city clusters, rather than across cities, but the city clusters are not necessarily geographically contiguous.

Hanink (1996) examines the impact of regional versus national market conditions on local vacancy rates in the retail sector. His research indicates that the local vacancy rate is primarily influenced by the vacancy rates in surrounding MSAs, that is, he finds evidence of strong spatial autocorrelation among the cities in his sample. The implication is that diversification can be achieved by diversifying across geographic regions that are regionally contiguous.
Benjamin, Jud and Winkler (2000) also study the variations in market vacancy rates in the retail space market. They report results similar to Hanink (1996) for vacancy rate levels, but they find further that changes in vacancy rates evidence little correlation across time or space. They report that changes in the national vacancy rate are associated with widely different changes in metropolitan vacancy rates, so that proper diversification may require more than simply spreading investments among a few large geographic regions.

\section{Methodology and Data}

This study reexamines the benefits of market diversification across retail real estate markets. Assessment of the benefits of diversification requires the measurement of market returns and risks. Most of the diversification research has utilized return series derived from indexes developed by NCREIF. Unfortunately, the NCREIF data track quarterly appraisal-based returns by sector for a limited number of metropolitan statistical areas (MSAs), and the return series apply only to real estate held in private equity portfolios. For REIT portfolios, there is no geographic return series that managers can use when applying standardized asset allocation methodologies.

Lacking a comprehensive return series for retail real estate investment, this study uses occupancy rates obtained from F.W. Dodge. While occupancy rates are not a complete measure of real estate returns, they are significantly correlated. The correlation coefficient for the two series is 0.39 , which is statistically significant at the .005 level. Exhibit 1 shows the relationship between the NCREIF retail real estate return series and the F. W. Dodge retail occupancy series from 1987:1 through 2000: 1. From Exhibit 1, it is clear that the series cycle move together very closely.

The F. W. Dodge series is used to estimate optimized portfolios on an efficient frontier of real estate investment in the retail sector in fifty-eight metropolitan markets. Using this approach permits an evaluation of mean-variance efficiency for portfolios covering a larger number of MSAs than 


\section{Exhibit 1}

NCREIF Returns and Occupancy Rates (normalized scale)

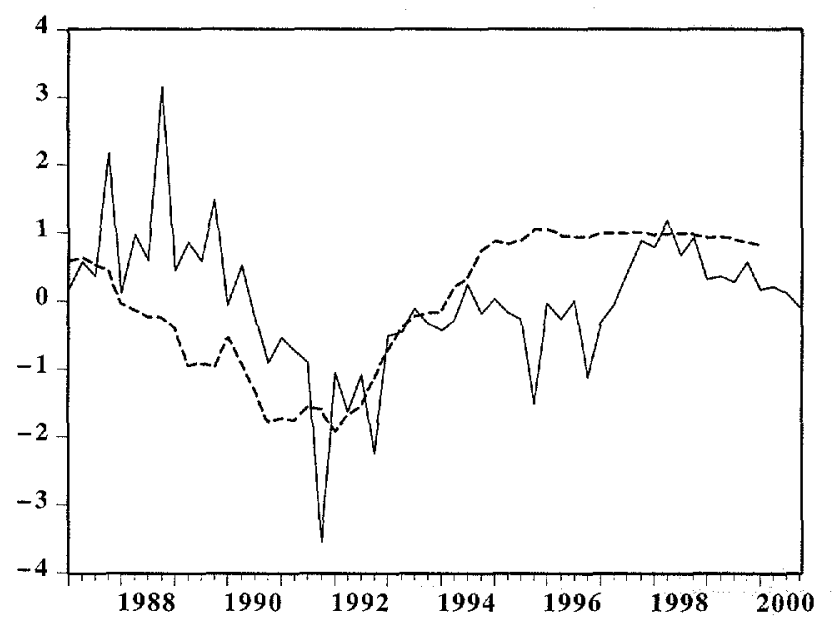

— NCREIF Retail Returns ---- F. W. Dodge Occupancy Series

is available with the NCREIF series. By focusing on the retail sector, the benefits of geographic diversification can be concentrated on, abstract of sector diversification issues.

Modern portfolio theory developed by Markowitz (1952) and the use of optimization techniques permit the determination of efficient opportunity sets with occupancy risk/return profiles and accompanying allocations. If retail real estate markets are effectively integrated, then market diversification will not provide significant reductions in risk. The purpose of this research is to investigate the extent of integration of the retail space markets and determine the allocations among MSAs necessary to achieve efficient opportunity sets.

While the Markowitz model was originally designed for use in a stock portfolio context, the model has extensive possibilities for use in other contexts when covariance has a noticeable impact on the volatility of a portfolio of assets or markets. Recent research has applied the Markowitz model in such divergent areas as life-time consumption patterns, international investing, mutual fund investing, and holdings of foreign currencies. ${ }^{1}$

Suppose that the expected occupancy rate for $M S A_{i}$ is defined as $E\left(O_{i}\right)$, and $w_{i}$ is the percentage weight attributable to the occupancy rate of the MSA. Then the expected occupancy rate for a portfolio of $N$ metropolitan areas is defined as the weighted average of the individual expected occupancy rates in the $N$ metropolitan areas as follows:

$$
E\left(O_{p}\right)=\sum_{i=1}^{N} w_{i} E\left(O_{i}\right)
$$

The portfolio variance is the weighed sum of variance and covariance of occupancy rate terms for all combinations of occupancy rates in metropolitan areas $i$ and $j$ as follows:

$$
\operatorname{VAR}\left(O_{p}\right)=\sum_{i=1}^{N} \sum_{j=1}^{N} w_{i} w_{j} \sigma_{i j}
$$

Where $\sigma_{i j}$ is the variance term when $i=j$ and the covariance term when $i \neq j ; w_{i}$ and $w_{j}$ are the percentages allocated to each metropolitan area $i$ and $j$.

The efficient set is the mean-variance choices of metropolitan areas from the opportunity set of all MSAs, where for a given variance (or standard deviation), no other selection of opportunities offers a higher mean return. This is shown in Exhibit 2 as $A B$. The opportunity set $C D$ is not an optimal set because $A B$ offers a higher portfolio occupancy rate for a given risk (defined as the standard deviation of the portfolio occupancy rate). The line $C D$ could be a constrained set of metropolitan areas, or a misallocation of weights among the metropolitan areas.

This study seeks to identify the metropolitan areas that are part of the efficient set, and what allocations or weights are necessary for each MSA to become part of the efficient set. A second objective is to identify the efficient set for each region, and compare that efficient set to the broader efficient set that includes all metropolitan areas in the country. The weights that are associated with each MSA are constrained to be such that $0 \leq w_{i} \leq 1$ and $\sum_{i=1}^{N} w_{i}=1$. The identification of the efficient sets (including the metropolitan areas and weights) involves the maximization of Equation (1) 


\section{Exhibit 2 \\ Opportunity Sets of $\mathbf{N}$ Metropolitan Areas}

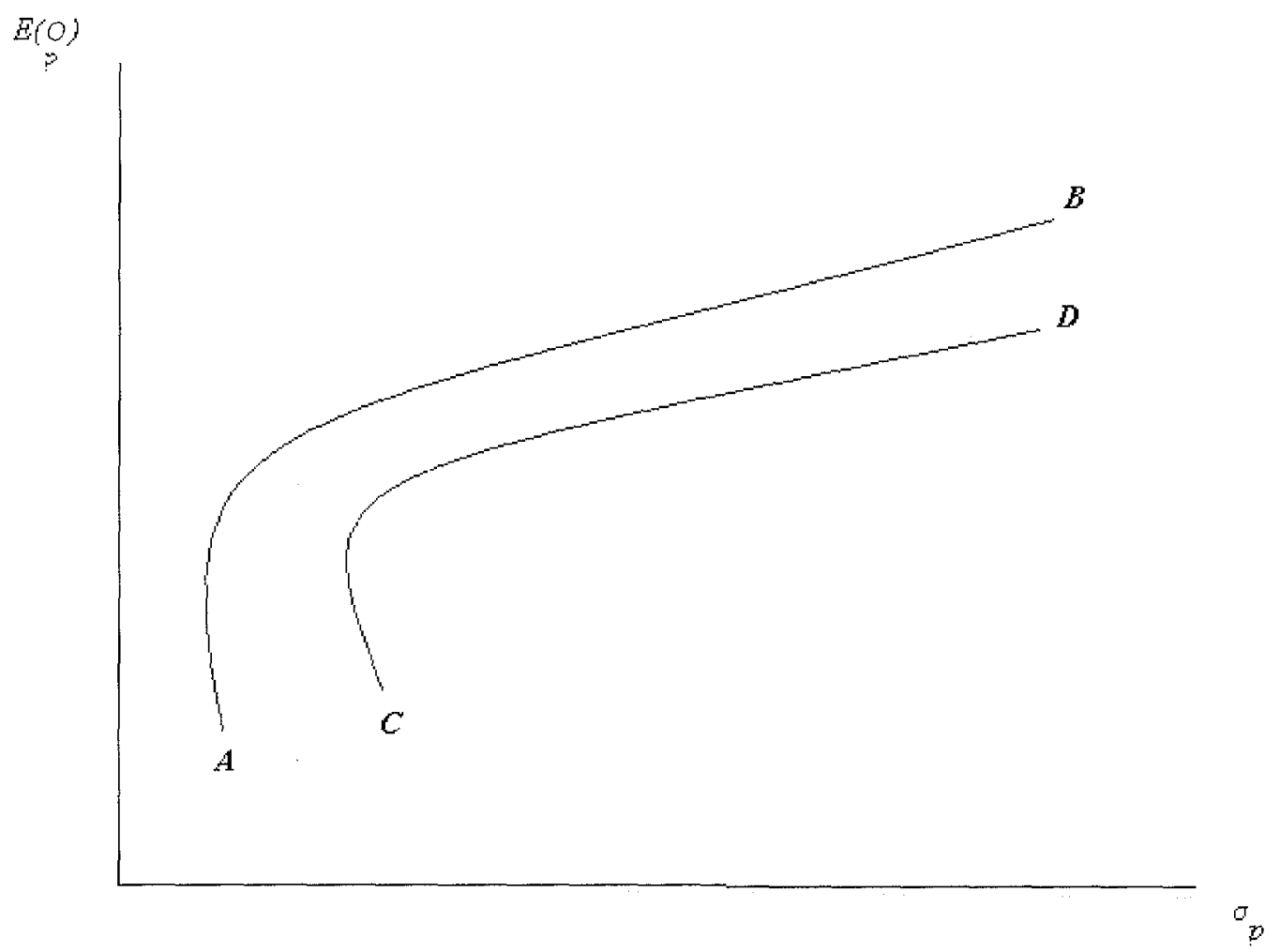

with respect to Equation (2), with constraints on $w_{i}$ as previously defined. ${ }^{2}$

The data for this study consists of quarterly retail occupancy rates for fifty-eight metropolitan statistical areas (MSAs) from 1987:1 to 2000:1, a period of time that encompasses a full cycle of expansion, recession and recovery. The retail occupancy rates reflect the interaction of demand and supply forces in fifty-eight metropolitan retail markets. The data set consists of 3,074 observations. The occupancy rate data, obtained from F.W. Dodge, cover the aggregate number of square feet of retail space in each market, excluding restaurants.

\section{Results}

The average occupancy rates from 1987:1 through 2000:1 across the fifty-eight MSAs are shown in Exhibit 3. In 1990:2, prior to the onset of the recession, the mean occupancy rate was $90.3 \%$. The rate did not return to its pre-recession level until 1993:1, six quarters after the national economy came out of recession in 1991:2. In the early 1990s, the mean occupancy rate rose steadily through 1995:4; thereafter, the rate has remained above 92\% through 2000:1.

In Exhibit 4, the occupancy rates are presented by MSA for 1987:1-2000:1. The average retail occupancy rate ranged from a high of $96.21 \%$ in San Francisco to a low of $83.03 \%$ in Fort WorthArlington. Several MSAs including Austin-San Marcos, Houston and Nashville have large variations in occupancy rates as indicated by the large standard deviations.

The risk/return occupancy profiles for the full sample of MSAs is presented in Exhibit 5. It is noteworthy that only twenty of the fifty-eight metropolitan areas are in the efficient opportunity set. These twenty metropolitan areas provide the highest occupancy rates for a given level of variation in the occupancy rates. Because thirty-eight MSAs had a zero-percent allocation, it would be necessary for an investor to hold retail space in only 
Exhibit 3

Occupancy Rates by Quarter from 1987-2000

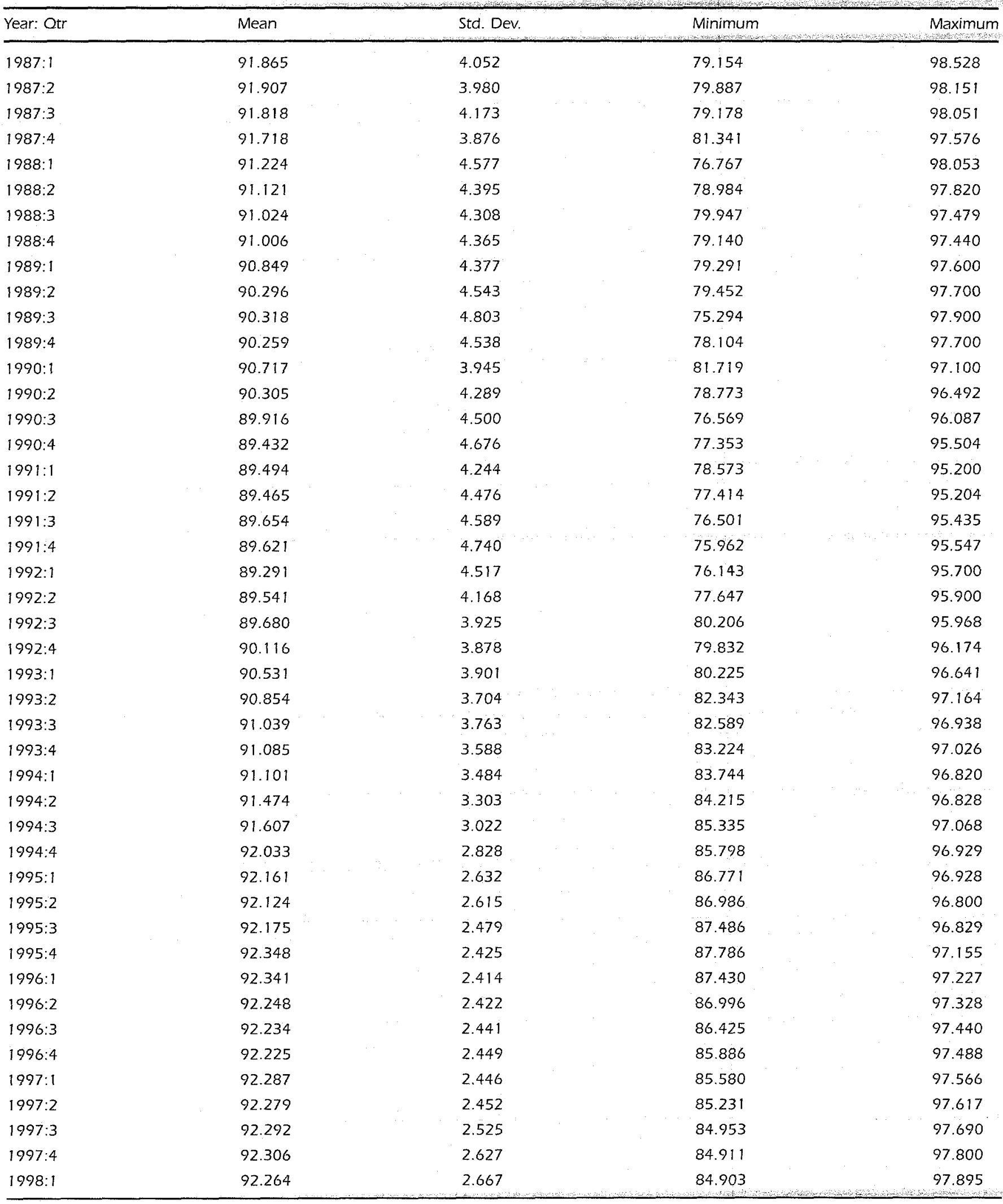




\begin{tabular}{llll}
\hline & \multicolumn{2}{c}{$\begin{array}{c}\text { Exhibit } \mathbf{3} \text { (Continued) } \\
\text { Occupancy Rates by Quarter from 1987-2000 }\end{array}$} \\
\hline Year: Otr & Mean & Std. Dev & Minimum \\
\hline $1998: 2$ & 92.275 & 2.735 & 84.984 \\
$1998: 3$ & 92.297 & 2.762 & 85.074 \\
$1998: 4$ & 92.265 & 2.804 & 85.046 \\
$1999: 1$ & 92.220 & 2.893 & 84.849 \\
$1999: 2$ & 92.240 & 2.891 & 84.744 \\
$1999: 3$ & 92.189 & 2.863 & 84.692 \\
$1999: 4$ & 92.157 & 2.779 & 84.034 \\
$2000: 1$ & 92.091 & 2.748 & 98.068 \\
\hline
\end{tabular}

\section{Exhibit 4}

Occupancy Rates by MSA from 1987-2000

\begin{tabular}{|c|c|c|c|c|}
\hline MSA/State Name & Mean & Std. Dev. & Min. & Max. \\
\hline Atlanta, GA & 92.044 & 2.079 & 86.439 & 94.513 \\
\hline Austin-San Marcos, TX & 87.719 & 4.069 & 81.705 & 94.368 \\
\hline Baltimore, MD & 93.219 & 1.385 & 89.066 & 95.892 \\
\hline Birmingham, AL & 93.652 & 1.083 & 92.123 & 95.599 \\
\hline Boston-Brockton, MA & 96.091 & 1.719 & 91.059 & 98.068 \\
\hline Chicago, IL & 92.174 & 1.836 & 84.938 & 94.215 \\
\hline Cincinnati, $\mathrm{OH}-\mathrm{KY}-\mathrm{IN}$ & 90.127 & 2.595 & 85.083 & 94.500 \\
\hline Cleveland-Lorain-Elyria, $\mathrm{OH}$ & 92.518 & 1.025 & 90.929 & 94.391 \\
\hline Columbus, $\mathrm{OH}$ & 92.084 & 1.280 & 90.501 & 94.678 \\
\hline Dallas, TX & 85.898 & 2.732 & 80.320 & 90.133 \\
\hline Fort Worth-Arlington, TX & 83.025 & 3.144 & 75.294 & 88.091 \\
\hline Greensboro-Winston-Salem-High Point, NC & 91.626 & 1.694 & 89.333 & 96.174 \\
\hline Greenville-Spartanburg-Anderson, SC & 89.120 & 1.986 & 85.092 & 92.400 \\
\hline Hartford, CT & 95.202 & 1.707 & 90.643 & 97.900 \\
\hline Honolulu, HI & 92.287 & 1.051 & 90.700 & 94.700 \\
\hline Houston, $\mathrm{TX}$ & 83.162 & 4.654 & 75.779 & 88.838 \\
\hline Indianapolis, IN & 93.673 & 2.016 & 91.371 & 97.118 \\
\hline Jacksonville, FL & 86.142 & 3.630 & 79.619 & 91.715 \\
\hline Kansas City, MO-KS & 92.336 & 2.162 & 88.650 & 95.574 \\
\hline New Haven-Bridgeport-Stamford, CT & 94.844 & 1.501 & 91.228 & 98.528 \\
\hline
\end{tabular}




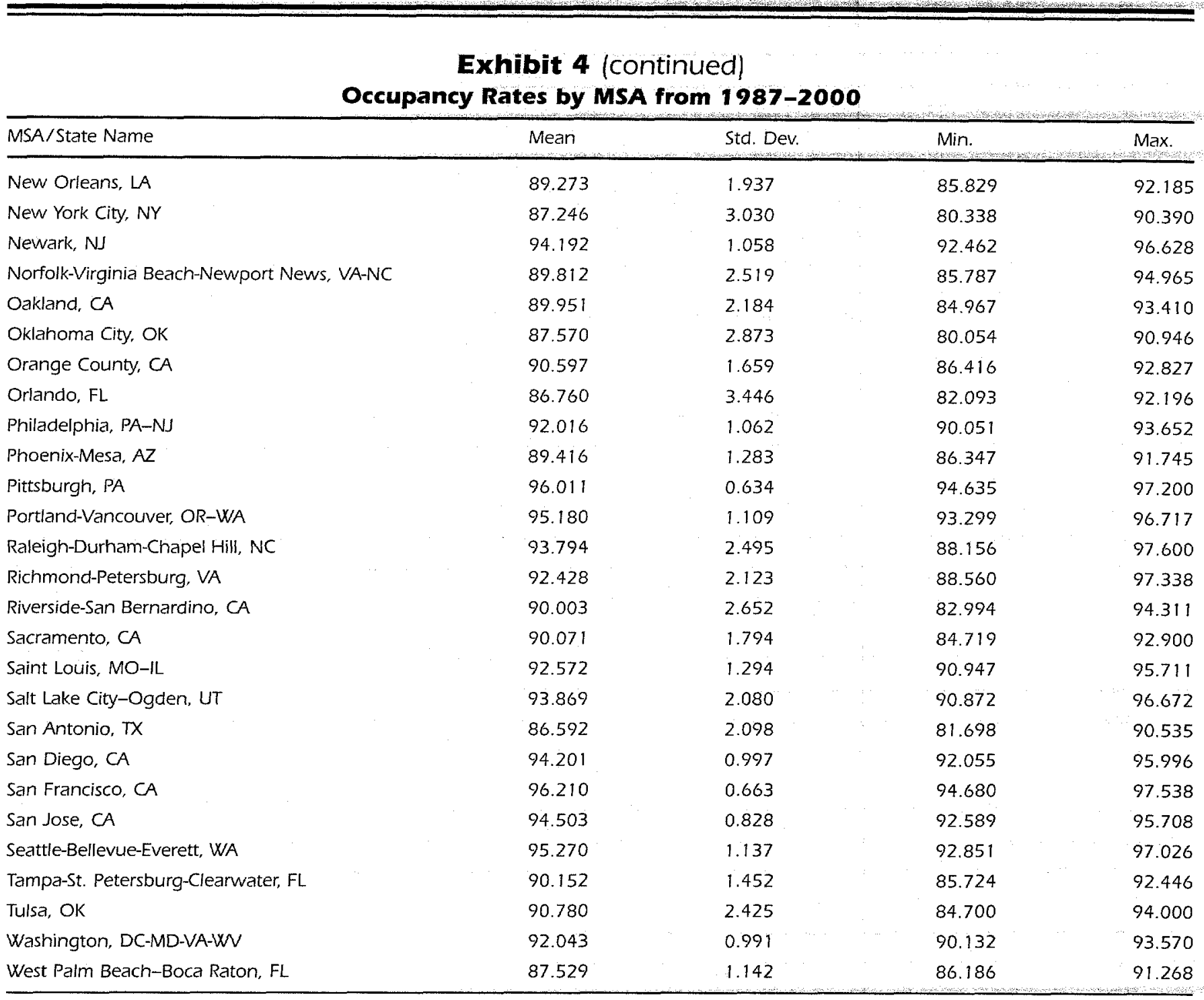

approximately one-third of the MSAs in the sample. The MSAs with the largest allocations include Hartford, Nassau-Suffolk, Newark, Pittsburgh, Raleigh-Durham-Chapel Hill, San Francisco, San Jose and Tulsa. The efficient opportunity set points are labeled EF 1 through EF 10; the occupancy rates for these efficient portfolios range from $92.28 \%$ to $96.21 \%$, while their respective portfolio standard deviations range from $0.06 \%$ to $0.63 \%$.

The risk/return occupancy profiles for the Midwest, Northeast, South and West are shown in Exhibits 6-9. An examination of the efficient opportunity set points for these regions reveals the Midwest and South to be inferior to the Northeast and West as the occupancy rates are lower and the variation higher in these regions. Interestingly, the South and West have half or more of the MSAs excluded from the efficient set, while the Northeast and Midwest only have $30 \%$ to $40 \%$ of those excluded.

The efficient opportunity sets for the regions are presented in Exhibit 10. The graph clearly shows the advantage of having allocations in MSAs from around the country. For example, although the West and Northeast appear to be the best performing regions, the results for the full sample of MSAs offers about a $1 \%$ higher occupancy rate at lower risk levels. Looking at the results in terms of risk, a comparable occupancy rate portfolio at lower levels of risk offers about half the risk or less 


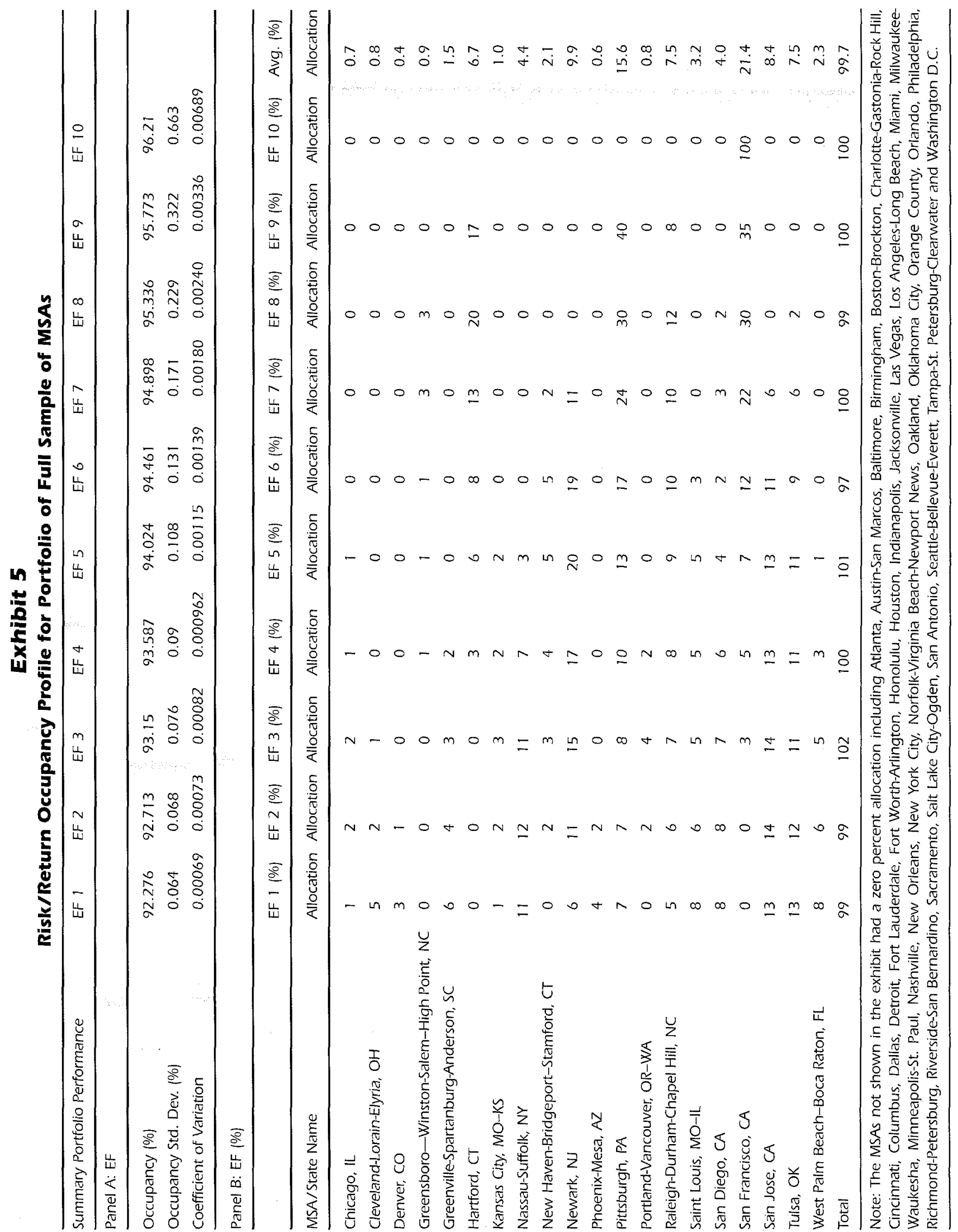




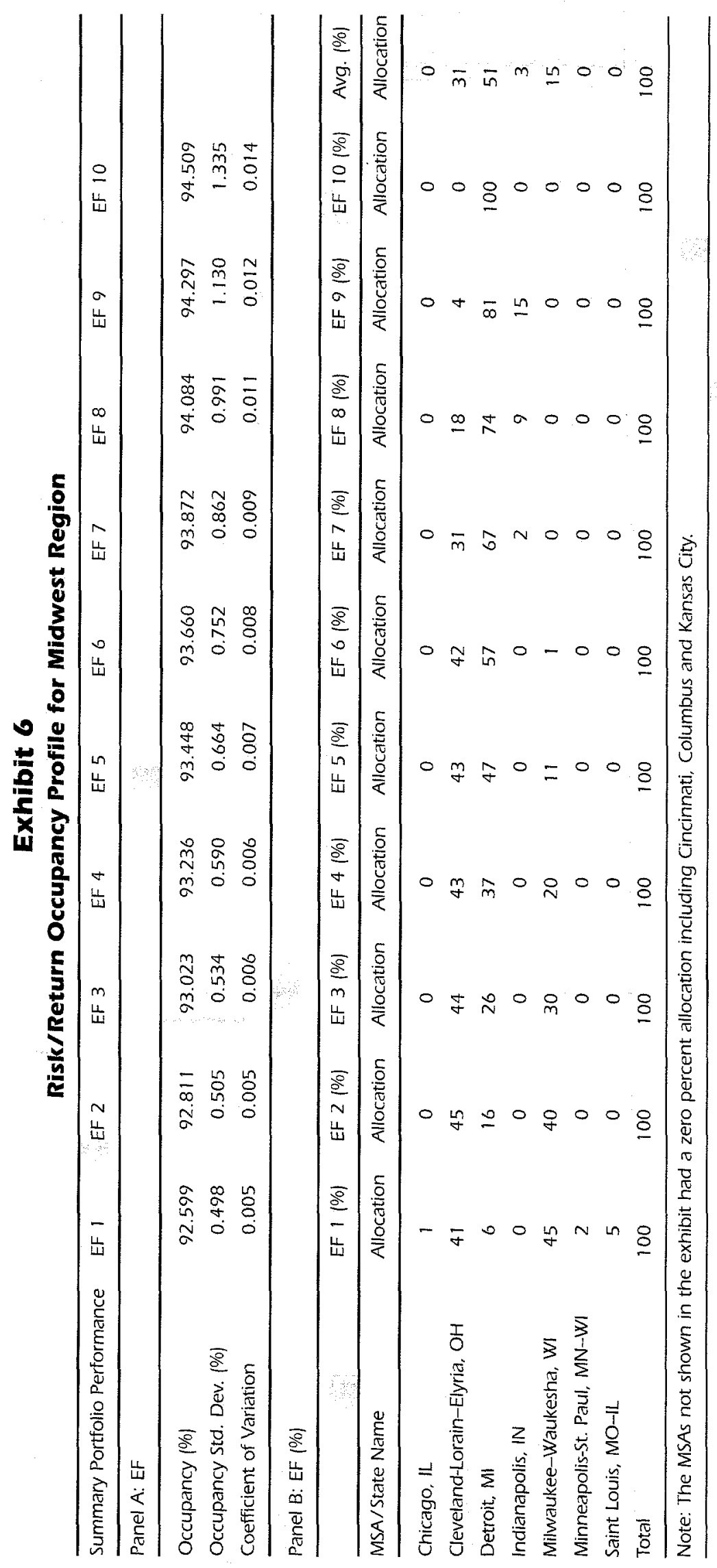




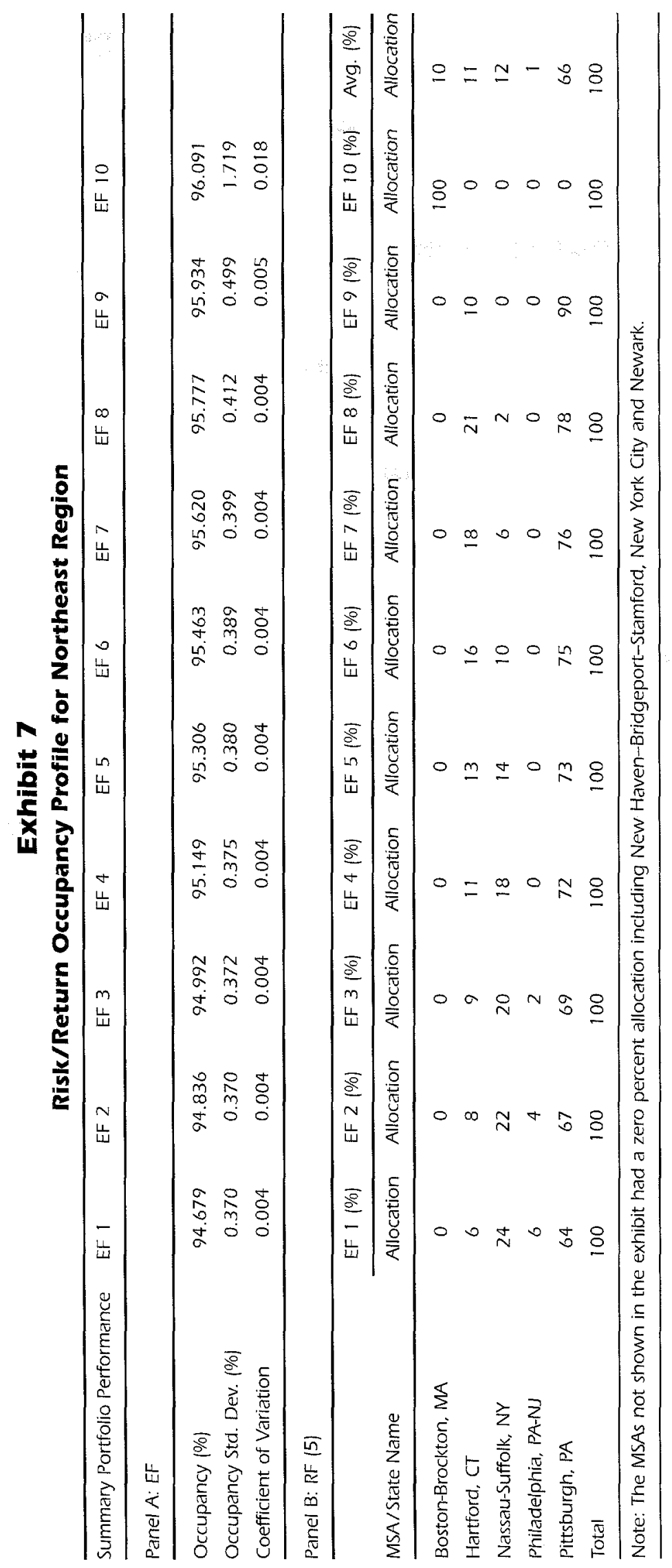




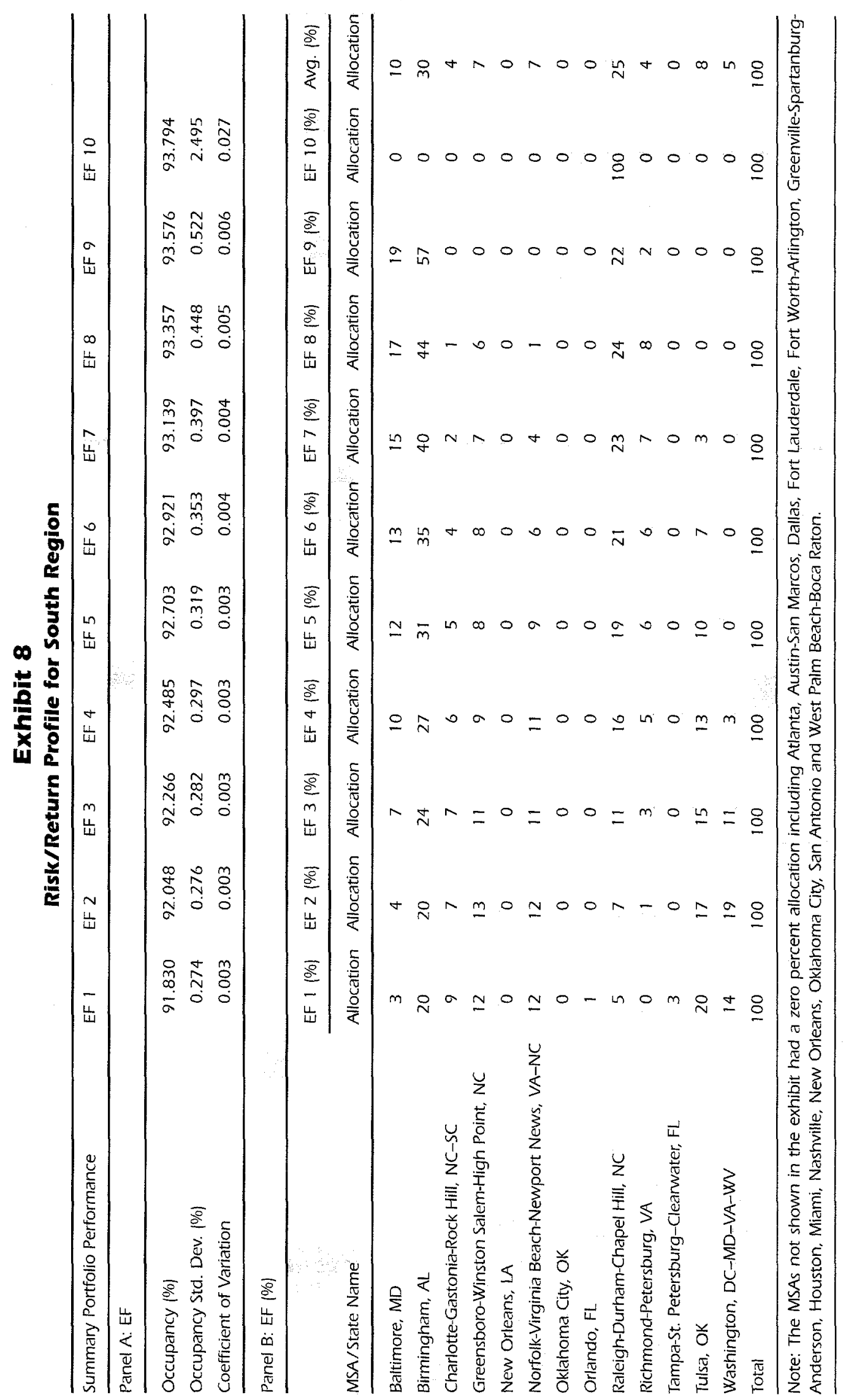




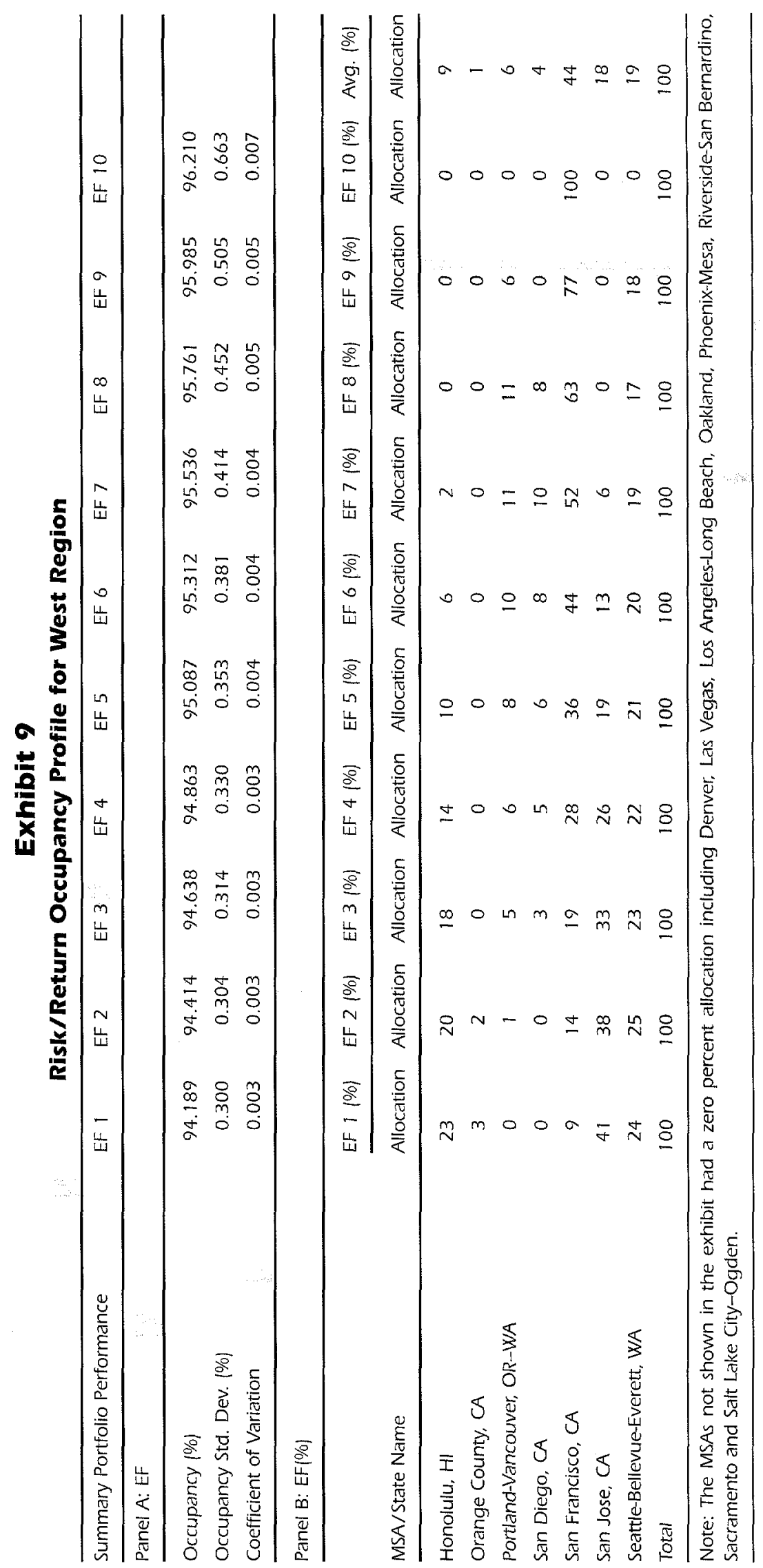




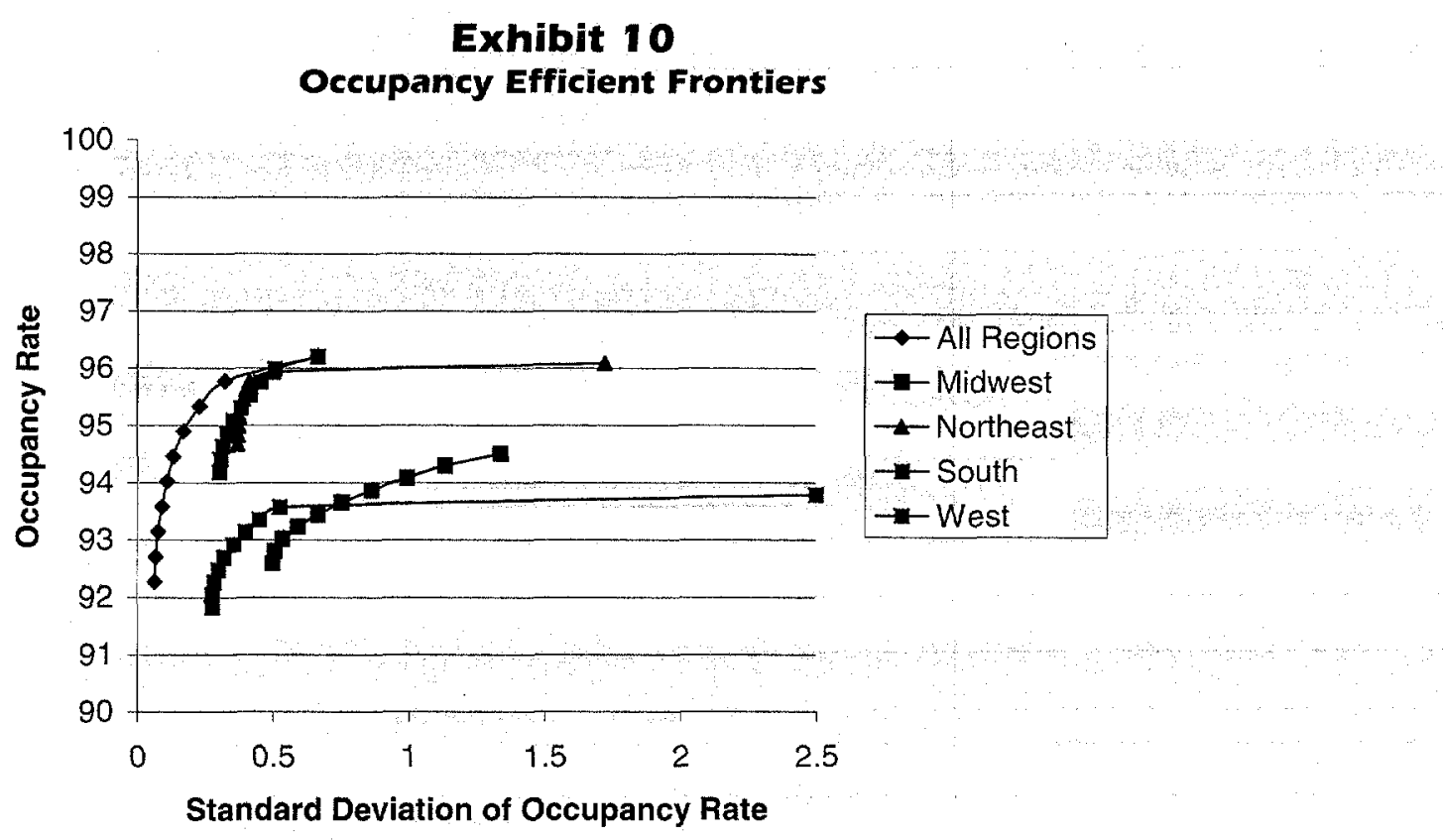

compared with the West or Northeast. The Midwest and South efficient frontiers are clearly dominated by the other regional efficient frontiers, and the Midwest, in particular, has much more risk at multiple levels of allocation. ${ }^{3}$

\section{Conclusion}

This study examines the integration of retail space markets using portfolio theory. The efficient opportunity sets and associated percentage allocations are determined for the entire sample of fifty-eight MSAs as well as for subsets for each region of the country. The data span fifty-three quarters starting the first quarter of 1987.

The findings indicate that retail space markets are not well integrated: some regions offer much higher performance in a risk/return occupancy context than others. Also, the occupancy risk/return performance improves substantially when allocations are not limited to particular regions. However, it is not necessary to invest in all fiftyeight MSAs to achieve a high degree of diversification benefit. In fact, only twenty of the fifty-eight regions are actually part of the efficient opportunity set, and, of those, only about half achieved significant allocations. Those metropolitan areas that enter into the efficient opportunity set at the national level are not necessarily "New Economy" MSAs. Rather, they are a mix of both "Old Economy" and "New Economy" types that have beneficial covariation in occupancy rate movements.

The findings are important to lenders, planners, developers, REIT portfolio managers and others who make real estate investment and portfolio decisions in the retail sector. The major findings of the research are:

- Retail space markets are not well integrated, suggesting that market diversification can produce significant reductions in risk for the same level of occupancy.

- A system of diversifying nationally among major metropolitan markets is superior to diversifying within major geographic regions, such as, the West or South.

- The most effective diversification strategy is achieved by investing in just 20 of the 58 metropolitan markets examined.

While this research remains to be confirmed with further work focused on other property types and using better measures of returns, it points to significant gains from market diversification. 


\section{Notes}

1. See, for example, Flavin and Yamashita (1998), Rowland and Tesar (1998), Baz, Breedon, Naik and Peress (2001) and Chamorro and Perez de Villarreal (2000).

2. The efficient sets were identified using Matlab 5 with the Statistics, Finance and Optimization Toolboxes.

3. The efficient frontiers for the Northeast and South are extended to high-risk levels only for the highest risk portfolio.

\section{References}

Baz, J., F. Breedon, V. Naik and J. Peress, Optimal Portfolios of Foreign Currencies, Journal of Portfolio Management, 2001, 28:1, 102-11.

Benjamin, J. D., G. D. Jud and D. T. Winkler, Retail Vacancy Rates: The Influence of National and Local Economic Conditions, Journal of Real Estate Portfolio Management, 2000, 6:3, 249-58.

Chamorro, J. M. and J. M. Perez de Villarreal, Mutual Fund Evaluation: A Portfolio Insurance Approach: A Heuristic Application in Spain, Mathematics and Economics, 2000, 27:1, $83-104$.

Corgel, J. B. and G. D. Gay, Local Economic Base, Geographic Diversification and Risk Management of Mortgage Portfolios, Journal of the American Real Estate and Urban Economics Association, 1987, 15:3, 256-67.

Flavin, M. and T. Yamashita, Owner-Occupied Housing and the Composition of the Household Portfolio over the Life Cycle, Cambridge, MA: National Bureau of Economic Research, Working paper 6389, 1998.
Goetzmann, W. N. and S. M. Wachter, Clustering Methods for Real Estate Portfolios, Real Estate Economics, 1995, 23:3, 271310 .

Hanink, D. M., How 'Local' are Local Office Markets?, Real Estate Economics, 1996, 24:3, 341-58.

Hartzell, D., J. S. Heckman and M. Miles, Diversification Categories in Investment Real Estate, Journal of the American Real Estate and Urban Economics Association, 1986, 14:2, 230-54.

Hartzell, D., D. Schulman and C. Wurtzebach, Refining the Analysis of Regional Diversification for Income Producing Real Estate, Journal of Real Estate Research, 1987, 2:2, 85-95.

Malizia, E. and R. A. Simons, Comparing Regional Classifications for Real Estate Portfolio Diversification, Journal of Real Estate Research, 1991, 6:1, 53-77.

Markowitz, H., Portfolio Selection, Journal of Finance, 1952, $7: 1,77-91$.

Mueller, G. R., Refining Economic Diversification Strategies for Real Estate Portfolios, Journal of Real Estate Research, 1993, 8:1, 55-68.

Rowland, P. F. and L. L. Tesar, Multinationals and the Gains from International Diversification, Cambridge, MA: National Bureau of Economic Research, Working paper 6733, 1998.

Seiler, M. J., J. R. Webb and F. C. N. Myer, Diversification Issues in Real Estate Investment, Journal of Real Estate Literature, 1999, 7:2, 163-79.

The authors thank the Joseph M. Bryan School of Business and Economics at the University of North Carolina at Greensboro for a 2001 summer grant that funded this research. 
Copyright $@ 2002$ EBSCO Publishing 